\title{
Syntheses of Isoxazoline-Based Amino Acids by Cycloaddition of Nitrile Oxides and Their Conversion into Highly Functionalized Bioactive Amino Acid Derivatives
}

\author{
Loránd Kiss, ${ }^{a}$ Melinda Nonn, ${ }^{\mathrm{a}, \mathrm{b}}$ Ferenc Fülöp*a,b \\ a Institute of Pharmaceutical Chemistry, University of Szeged, Eötvös u. 6, 6720 Szeged, Hungary \\ Fax 3662545705; E-mail: fulop@pharm.u-szeged.hu \\ b Stereochemistry Research Group of the Hungarian Academy of Sciences, University of Szeged, Eötvös u. 6, 6720 Szeged, Hungary \\ Received: 12.04.2012; Accepted after revision: 08.05.2012
}

\begin{abstract}
The present account illustrates the syntheses of isoxazoline-based amino acids by the cycloaddition of 1,3-dipolar nitrile oxides to the $\mathrm{C}-\mathrm{C}$ double bond of unsaturated amino acid derivatives, with focus on the regio- and stereoselectivities of the transformations. Emphasis is also placed on the syntheses of highly functionalized amino acids by means of isoxazoline ring opening. The syntheses of various pharmacologically active compounds and their analogues via the above strategies are described.
\end{abstract}

1 Introduction

2 1,3-Dipolar Cycloadditions of Nitrile Oxides

3 Syntheses of Isoxazoline-Based Amino Acids

3.1 Syntheses of Isoxazoline $\alpha$-Amino Acids

3.2 Syntheses of Isoxazoline $\gamma$-Amino Acids and Their Transformation into Bioactive Derivatives

3.3 Syntheses of Isoxazoline $\beta$-Amino Acids

3.3.1 Syntheses of Highly Functionalized Cyclic $\beta$-Amino Acids by 1,3-Dipolar Cycloaddition of Nitrile Oxides

4 Cycloaddition of Nitrile Oxides to Amino Acid Precursors

5 Summary and Outlook

Key words: amino acids, amino alcohols, cycloaddition, diastereoselectivity, heterocycles, ring opening, stereoselective synthesis

\section{$1 \quad$ Introduction}

The syntheses and applications of the isoxazoline-based amino acids comprise a relatively new topic in amino acid chemistry. In consequence of their important pharmacological potential, these types of derivatives have been at the focus of interest in synthetic and medicinal chemistry during the past ten years. The aim of the present account is to provide an insight into the most relevant results relating to synthetic investigations of isoxazoline-based amino acids, with the focus mainly on the conformationally rigid analogues, and their transformation into highly functionalized derivatives with pharmacological potential.

Isoxazolines are versatile intermediates for the syntheses of a number of bioactive compounds. Substituted isoxazolines exhibit, for example, anti-influenza activity or antifungal properties. ${ }^{1} 1,3$-Dipolar cycloaddition is a method

SYNTHESIS 2012, 44, 1951-1963

Advanced online publication: 05.06 .2012

DOI: 10.1055/s-0031-1290373; Art ID: SS-2012-E0347-SR

(C) Georg Thieme Verlag Stuttgart · New York that is widely used for the construction of heterocycles, among them isoxazolines, or for the syntheses of various highly functionalized molecules.

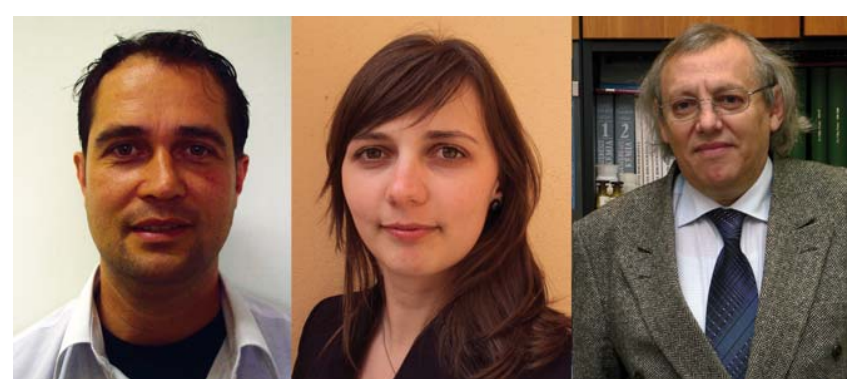

Loránd Kiss graduated chemistry in 1997 from Babes-Bolyai University, Faculty of Chemistry and Chemical Engineering (Cluj-Napoca, Kolozsvar, Romania). He received his Ph.D. degree in 2002 from Debrecen University, Department of Organic Chemistry, (Hungary) under the supervision of Professor Sándor Antus, working in the field of asymmetric syntheses of O-containing heterocyclic natural products. In 2003 he joined the research institute of Professor Ferenc Fülöp, at Institute of Pharmaceutical Chemistry, University of Szeged. He was postdoc in the laboratory of Professor Norbert De Kimpe at Ghent University, and in the laboratory of Professor Santos Fustero, Department of Organic Chemistry, University of Valencia. He is lecturer in Institute of Pharmaceutical Chemistry, University of Szeged. His recent scientific interest is directed toward the selective functionalization of alicyclic and heterocyclic $\beta$-amino acids, and stereoselective synthesis of highly functionalized carbocyclic amino alcohols.

Melinda Nonn graduated as chemist in 2007 from Babes-Bolyai University, Faculty of Chemistry and Chemical Engineering (Cluj-Napoca, Kolozsvar, Romania). In 2007 she started her Ph.D. at the Institute of Pharmaceutical Chemistry, University of Szeged (Hungary) under the supervision of Ferenc Fülöp. Her Ph.D. topic has focused on the stereoand regioselective transformations of alicyclic $\beta$-amino acids. In 2012 she became a team member of the Research Group of Stereochemistry of the Hungarian Academy of Sciences and University of Szeged. Her recent interest includes the synthesis of highly functionalized cyclic $\beta$ amino acids by 1,3-dipolar cycloaddition and the development of asymmetric synthetic methods toward the preparation of this class of derivatives.

Ferenc Fülöp was born in Szank, Hungary, in 1952. He received his M.Sc. in chemistry in 1975 and his Ph.D. in 1979, from József Attila University, Szeged, Hungary, under the supervision of Professor Gábor Bernáth. In 1991, he was appointed full professor at the Institute of Pharmaceutical Chemistry, University of Szeged, and since 1998 has been head of the Institute. He has a wide range of research interests in heterocyclic chemistry, including isoquinolines, saturated 1,3-heterocycles, and the ring-chain tautomerism of 1,3-heterocycles. His recent activities have focused on the use of amino alcohols and $\beta$-amino acids in enzymatic transformations, asymmetric syntheses, foldamer construction, and combinatorial chemistry, with a view to the development of pharmacologically active compounds. Since 2009 he has chaired a European COST action entitled 'Functional peptidomimetic foldamers: from unnatural amino acids to self-assembling nanomaterials.' 
The cycloaddition proceeds between a dipolarophile (e.g., alkenes, alkynes, carbonyls, or nitriles) and a 1,3-dipolar agent (Scheme 1).

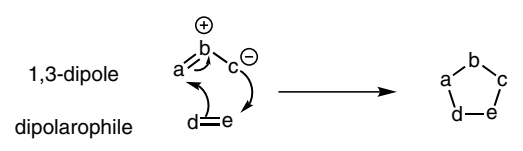

Scheme 1 General scheme of 1,3-dipolar cycloaddition

1,3-Dipoles involve three-atom $\pi$-electron systems, with four $\pi$-electrons delocalized over the three atoms. Some important 1,3-dipoles are nitrile oxides, nitrones, azides, nitrile imines, diazoalkanes, carbonyl ylides, and nitrile ylides. The 1,3-dipoles can be divided into two types: the allyl type, such as nitrones, azomethine ylides, azomethine imines, carbonyl ylides, and carbonyl imines, and the propargyl-allenyl type, such as nitrile oxides, nitrile imines, nitrile ylides, diazoalkanes, and azides (Figure 1).

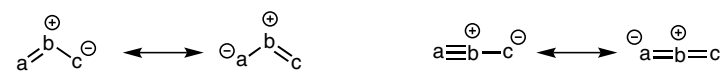

$$
\begin{aligned}
& \text { allyl type propargyl-allenyl type }
\end{aligned}
$$

Figure 1 Classification of 1,3-dipoles

The dipolarophile can be almost any compound containing a double or triple bond, such as $\mathrm{C} \equiv \mathrm{C}, \mathrm{C}=\mathrm{C}, \mathrm{C} \equiv \mathrm{N}$, $\mathrm{C}=\mathrm{N}, \mathrm{C}=\mathrm{O}$, or $\mathrm{C}=\mathrm{S}$. The cycloaddition of 1,3-dipoles to dipolarophiles may occur in a synchronous, concerted process, as proposed by Huisgen, or via a stepwise, diradical pathway, as favored by Firestone (Scheme 2). ${ }^{2}$

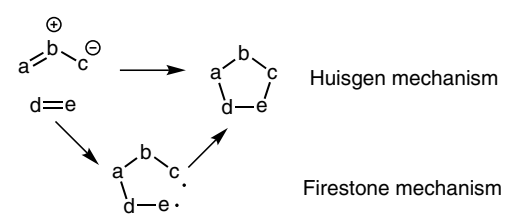

Scheme 2 Mechanisms of the 1,3-dipolar cycloaddition
2

\section{1,3-Dipolar Cycloadditions of Nitrile Oxides}

The 1,3-dipolar cycloaddition of nitrile oxides to alkenes is a powerful and efficient method for the synthesis of isoxazolines. ${ }^{3}$ Nitrile oxides are 1,3-dipoles of propargylallenyl type and their additions to yield isoxazolines may follow a concerted or a diradical mechanism. ${ }^{2 b}$

As nitrile oxides are reactive, relatively unstable dipoles, they are generated in situ in the reaction, mainly by two different routes: from hydroximoyl halides $(\mathrm{X}=\mathrm{Br}$ or $\mathrm{Cl}$, Huisgen methodology), or from primary nitroalkanes (Mukaiyama methodology) [Scheme 3 (a)]. 3a

According to the Huisgen procedure, nitrile oxides are generated from oximes in two steps: the halogenation of an aldoxime to give a hydroximoyl halide, followed by dehydrohalogenation with a base. The halogenation of oximes may be carried out, in general, with $N$-bromo- or $N$ chlorosuccinimide or sodium hypochlorite solution. ${ }^{2 a}$ Novel halogenating agents have recently been used efficiently for the generation of hydroximic acid halides: chloramine- $\mathrm{T}$, silica gel, ${ }^{4 \mathrm{a}}$ (diacetoxyiodo)benzene, and trifluoroacetic acid. ${ }^{4 \mathrm{~b}}$ The bases most commonly applied for the dehydrohalogenation are tertiary amines such as triethylamine [Scheme $3(\mathrm{~b})]^{2 \mathrm{~b}}$

The other method (that of Mukaiyama) for the in situ generation of nitrile oxides is the dehydration of primary nitroalkanes. The transformation is accomplished in the presence of a base. The dehydration agents used are phenyl isocyanate, di-tert-butyl dicarbonate, ethyl chloroformate, benzenesulfonyl chloride, dimethylaminosulfur trifluoride, acetic anhydride, etc.; in general, the base is triethylamine. A possible mechanism for the preparation of a nitrile oxide from a primary nitroalkane is shown in Scheme 3 (c). ${ }^{2}$

The cycloadditions of nitrile oxides to symmetrical alkenes are stereospecific transformations leading from $Z$ alkenes to cis-isoxazolines, and from $E$-alkenes to transisoxazolines [Scheme $4(\mathrm{a})$. $^{2 \mathrm{~b}}$
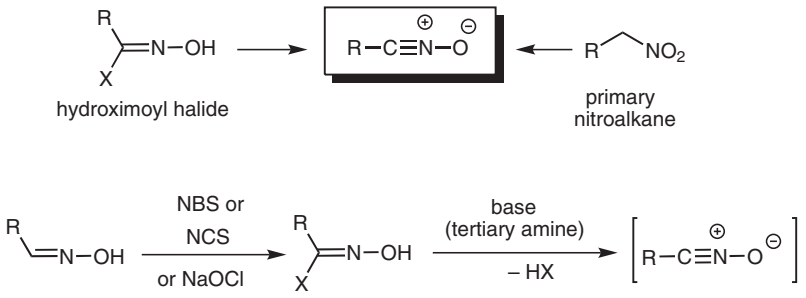

$\mathrm{X}=\mathrm{Cl}, \mathrm{Br}$

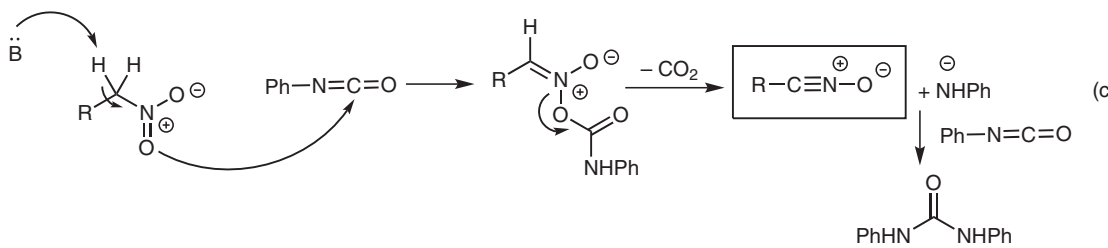

Scheme 3 Generation of nitrile oxides 


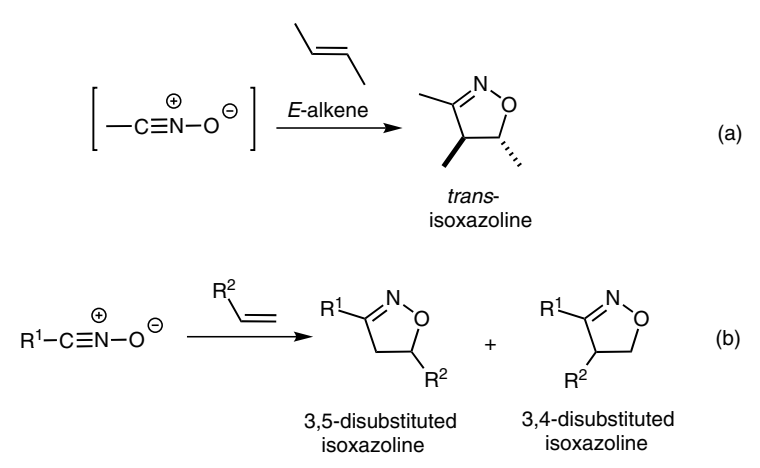

Scheme 4 Additions of nitrile oxides to alkenes

The cycloaddition of a nitrile oxide to a monosubstituted olefin can lead to two regioisomers, either the 3,4-disubstituted or the 3,5-disubstituted cycloadduct [Scheme 4 (b)], the regioselectivity being determined by steric and electronic effects. The 3,4-disubstituted isoxazoline is favored when strongly electron-withdrawing substituents are present on the dipolarophile; in the case of electrondonating substituents, formation of the 3,5-disubstituted isoxazoline is observed. ${ }^{2 a}$

When electron-rich and conjugated alkenes are applied in the cycloaddition, the regioselectivity is dipole-LUMOcontrolled. Accordingly, the carbon atom of the nitrile oxide attacks the terminal carbon atom of the alkene, resulting exclusively in the 3,5-disubstituted isoxazoline (Figure 2). In cycloadditions to electron-deficient dipolarophiles, both dipole-HOMO and dipole-LUMO interactions are significant, and mixtures of regioisomers are formed. In general, the 1,3-dipolar cycloadditions of nitrile oxides to disubstituted alkenes lead to mixtures of regioisomers. ${ }^{2 b}$

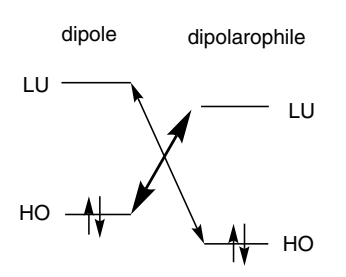

HO-controlled

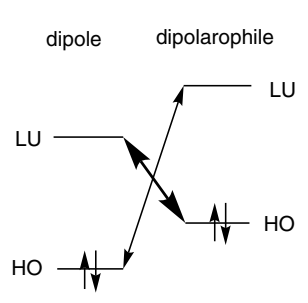

LU-controlled
Figure 2 Frontier molecular aspects of nitrile oxide cycloaddition
Isoxazolines are of considerable importance in synthetic chemistry, since they are precursors of imino alcohols, hydroxy ketones, and amino alcohols (Scheme 5). ${ }^{5}$

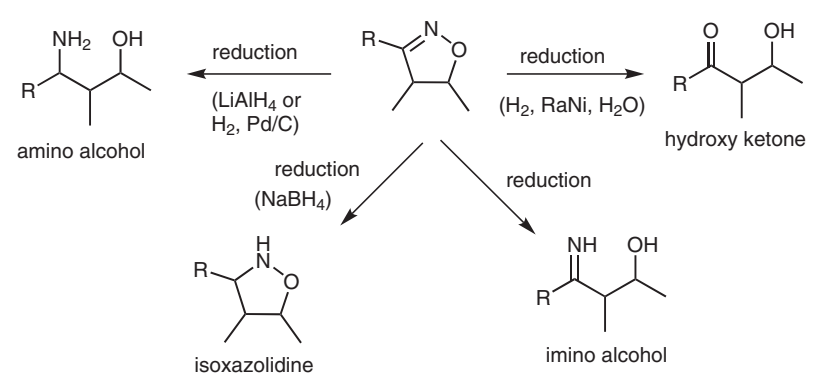

Scheme 5 Reductive transformations of isoxazolines

A wide range of reducing agents are applied in these transformations, such as $\mathrm{LiAlH}_{4}, \mathrm{NaBH}_{4}$, or catalytic hydrogenation in the presence of noble metals (Pd or Pt) or Raney nickel. ${ }^{5 a, b}$ Mild agents, such as $\mathrm{SmI}_{2}$ or $\mathrm{Fe} / \mathrm{NH}_{4} \mathrm{Cl}$, which tolerate different functional groups, have also been described for reduction of the isoxazoline ring. ${ }^{5 c, d}$ Asymmetric versions of the above reductions for the syntheses of enantiomerically pure amino alcohols or amino acids have been performed using borane/chiral ligand systems or through the reduction of readily available chiral isoxazolines..$^{\text {se-h }}$

\section{Syntheses of Isoxazoline-Based Amino Acids}

\subsection{Syntheses of Isoxazoline $\alpha$-Amino Acids}

Various isoxazoline-containing cyclopropane $\alpha$-amino acid derivatives have been synthesized via the dipolar cycloaddition of nitrile oxides and investigated as conformationally constrained homologues of glutamic acid. ${ }^{6}$

When cyclopropane $\alpha$-amino acid $\mathbf{1}$, with a vinylic $\mathrm{C}=\mathrm{C}$ bond, was subjected to dipolar cycloaddition with a nitrile oxide generated from ethyl 2-chloro-2-(hydroxyimino)acetate in the presence of sodium hydrogen carbonate as a base, the reaction resulted regioselectively in isoxazolinecontaining stereoisomers $\mathbf{2}$ and $\mathbf{3}$ with an ester group on the isoxazoline ring, in a ratio of approximately 1.5:1 (Scheme 6).

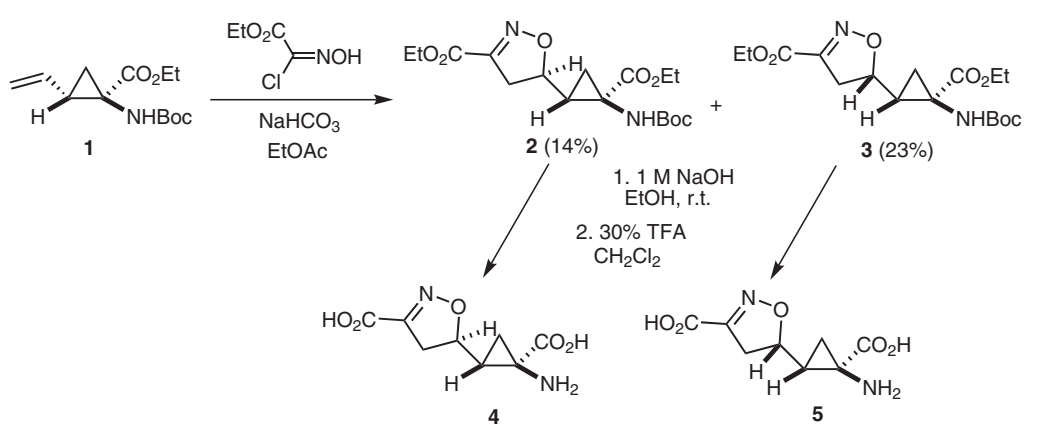

Scheme 6 


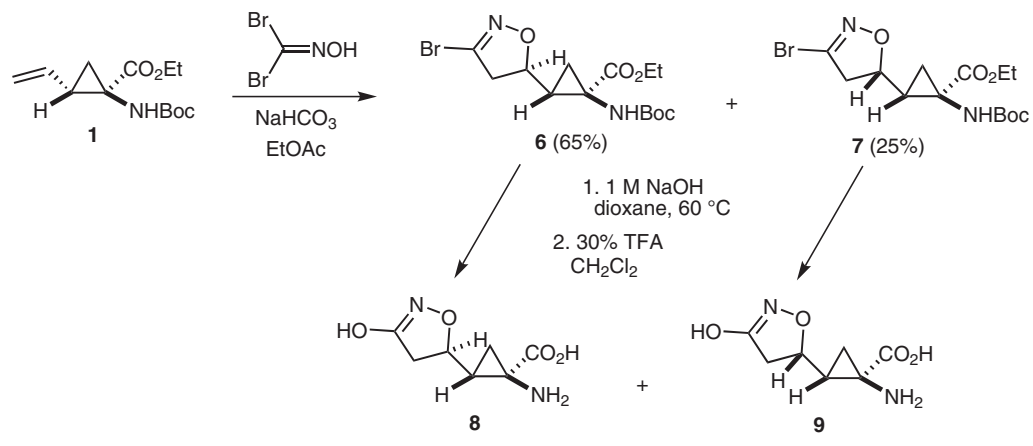

\section{Scheme 7}

Ester hydrolysis and $N$-Boc deprotection of $\mathbf{2}$ and $\mathbf{3}$ produced the isoxazoline-based cyclopropane amino acids 4 and $\mathbf{5}$ as conformationally restricted glutamate analogues.

In contrast, when the nitrile oxide was generated from dibromoformaldoxime and reacted with $\mathbf{1}$, the cycloaddition proceeded regioselectively with inverse stereoselectivity, furnishing isoxazoline-containing amino acid stereoisomers 6 and 7 in a ratio of 2.6:1 (Scheme 7). ${ }^{6}$

N-Deprotection of stereoisomers 6 and 7 with trifluoroacetic acid and hydrolysis in the presence of sodium hydroxide with replacement of the bromine on the isoxazoline skeleton afforded amino acid derivatives $\mathbf{8}$ and 9 (Scheme 7).

Conformationally restricted spiroisoxazoline-containing glutamate analogues have been synthesized by the addition of nitrile oxides [derived from ethyl 2-chloro-2(hydroxyimino)acetate or dibromoformaldoxime] to enantiomerically pure proline derivative $(S)-\mathbf{1 0}$, in which there is an extracyclic olefinic bond. In both cases, the reaction took place regioselectively, giving two stereoisomers, 11/12 and 13/14, in a ratio of $1: 3$ and $1: 4$, respectively (Scheme 8). ${ }^{6}$

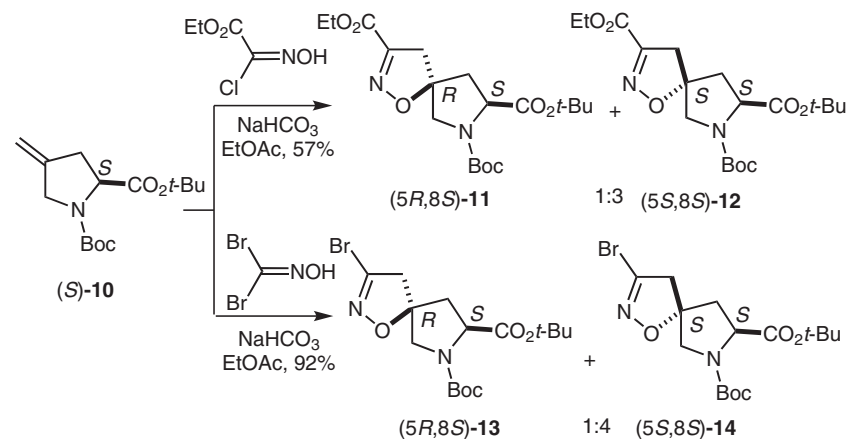

Scheme 8

These derivatives, $\mathbf{1 1} / \mathbf{1 2}$ and $\mathbf{1 3} / \mathbf{1 4}$, underwent easy transformation to the corresponding enantiomerically pure spiroisoxazoline amino acid derivatives. ${ }^{6}$

The counterpart enantiomers could be prepared via the same route, starting from enantiomerically pure $(R)-\mathbf{1 0}{ }^{6}$

Another proline derivative, $(-)-S-\mathbf{1 5}$, with the olefinic bond in the ring, was transformed by the cycloaddition of nitrile oxides to isoxazoline-fused cyclic amino acids as conformationally constrained aspartate or glutamate analogues, inhibitors of excitatory amino acid transporters. The cycloaddition of bromonitrile oxide to (-)-S-15 produced three of the four possible stereoisomers 16-18, in $13 \%, 25 \%$, and $27 \%$ yields, respectively. Compound $\mathbf{1 6}$ could be separated from $\mathbf{1 7}$ and $\mathbf{1 8}$ by chromatography (Scheme 9). ${ }^{7}$

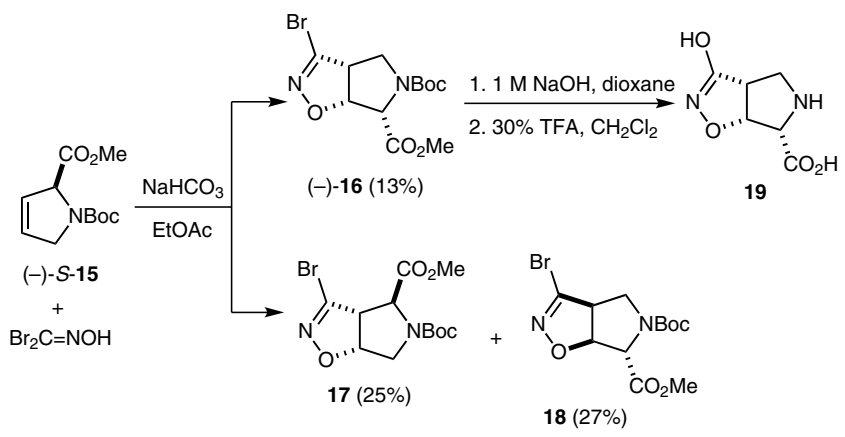

Scheme 9

Isoxazoline-containing amino acid enantiomer 19 was prepared from 16 by standard deprotection methodology (Scheme 9).

The mixture of isomers $\mathbf{1 7}$ and $\mathbf{1 8}$ was transformed to a mixture of $\mathbf{2 0}$ and 21, treatment of which with (-)-(1S)2,10-camphorsultam yielded diastereoisomers $\mathbf{2 2}$ and $\mathbf{2 3}$, which were separated by chromatography. N-Deprotection with trifluoroacetic acid, hydrolysis, and bromine removal with sodium hydroxide gave the corresponding enantiomerically pure isoxazoline-fused proline derivatives 24 and $\mathbf{2 5}$ (Scheme 10). ${ }^{7}$
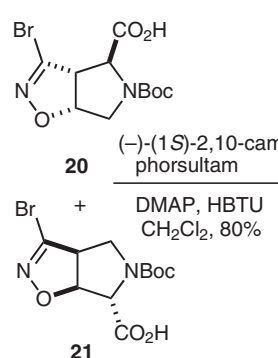

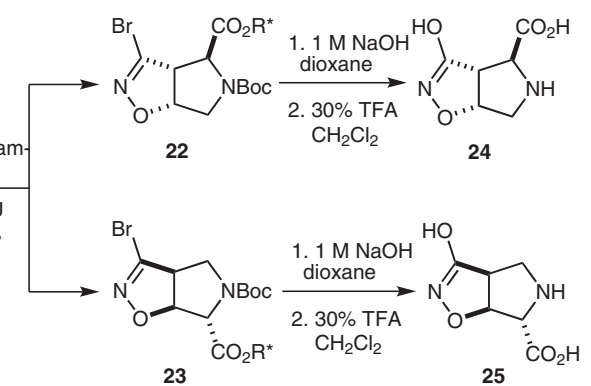

Scheme 10 
Novel acyclic isoxazoline-containing glutamate analogues that behave as $N$-methyl-D-aspartic acid (NMDA) receptor antagonists, were successfully synthesized by the addition of nitrile oxide [derived from ethyl 2-chloro-2(hydroxyimino)acetate] to unsaturated acyclic aminocarboxylate 26. The reaction, carried out under microwave irradiation conditions, led regioselectively to four isoxazoline-based amino ester stereoisomers 27-30, which were separated and isolated by chromatography (Scheme 11).

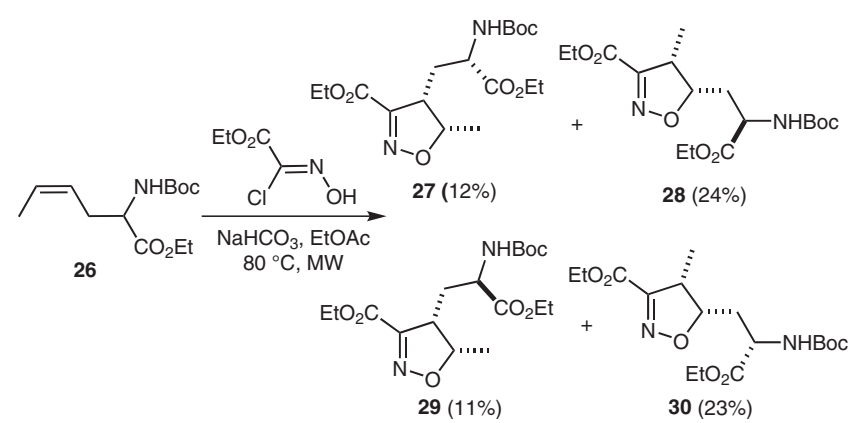

Scheme 11

These isoxazoline amino esters $\mathbf{2 7 - 3 0}$ were converted by hydrolysis and N-Boc deprotection into the corresponding amino acids. $^{8}$

The cyclopentene $\alpha$-amino ester $\mathbf{3 1}$ was a suitable starting compound for the preparation of conformationally constrained homologues of glutamic acids, which act as neuroprotective agents. On treatment with ethyl 2-chloro-2(hydroxyimino)acetate in the presence of base by the Huisgen method, the ethoxycarbonylformonitrile oxide generated by cycloaddition stereoselectively afforded isoxazoline-fused aminocyclopentanecarboxylates $\mathbf{3 2}$ and 33 in a ratio of approximately 5:1, with the carbamate and isoxazoline skeleton in a cis relationship in the major stereoisomer 32 (Scheme 12); these products were separated and isolated by chromatography.

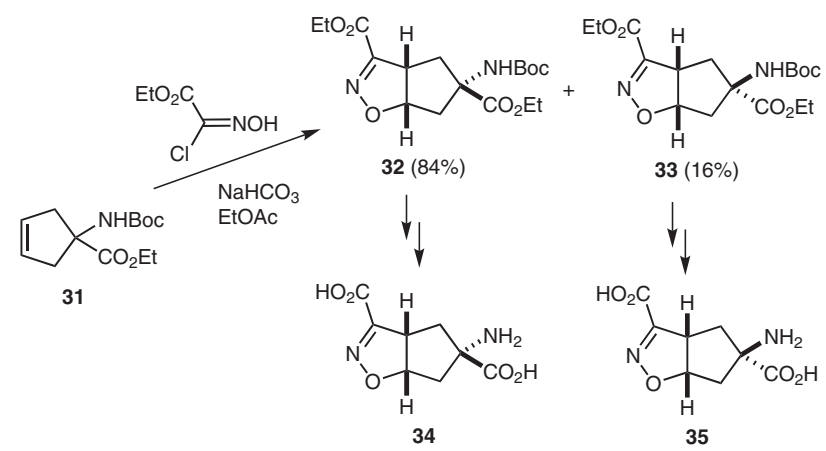

Scheme 12

The cis selectivity of the cycloaddition is explained by the $\mathrm{H}$-bond directing effect in the transition state of the reaction. The intermolecular H-bonding interaction between NHBoc and the nitrile oxide in the transition state (Figure
3) led to isoxazoline-fused derivative $\mathbf{3 2}$ as the major product.

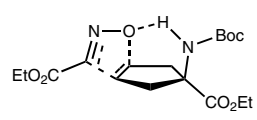

Figure 3

Through ester and N-deprotection under standard conditions, the conformationally constrained isoxazoline carboxylates 32 and $\mathbf{3 3}$ yielded amino acids $\mathbf{3 4}$ and $\mathbf{3 5}$ (Scheme 12). ${ }^{9}$

Cycloaddition to the di- $N$-Boc-protected cyclopentenecarboxylate ester $\mathbf{3 6}$ could be achieved with opposite selectivity. Because of the absence of the H-bond directing effect, the reaction was controlled by steric factors. It proceeded with inverse stereoselectivity to give isoxazolinefused carboxylates $\mathbf{3 7}$ and $\mathbf{3 8}$ in a ratio of 1:2, the major product being that in which the carbamate and isoxazoline ring were in the trans steric arrangement (Scheme 13). ${ }^{9}$

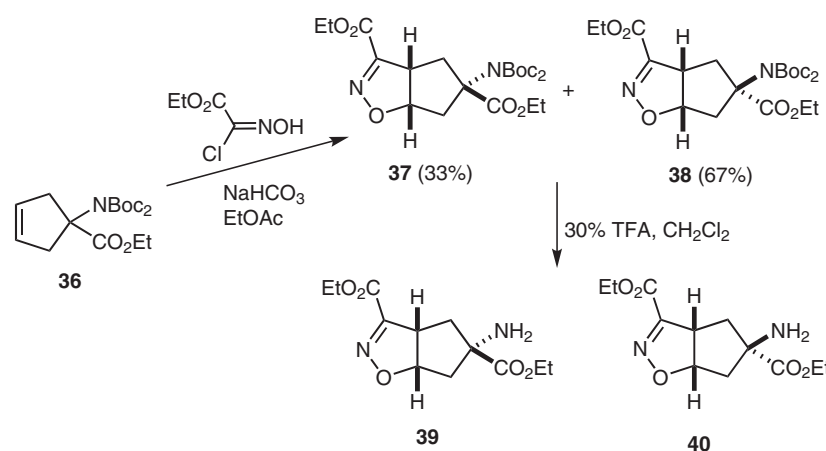

Scheme 13

Although amino esters $\mathbf{3 7}$ and $\mathbf{3 8}$ could not be separated, $\mathrm{N}$-deprotection of their mixture led to the earlier prepared amino ester 39 and a new stereoisomer 40, which were successfully separated and isolated by column chromatography.

Enantiomerically pure derivatives were synthesized by the same group of authors through the use of enzymatic resolution methods.

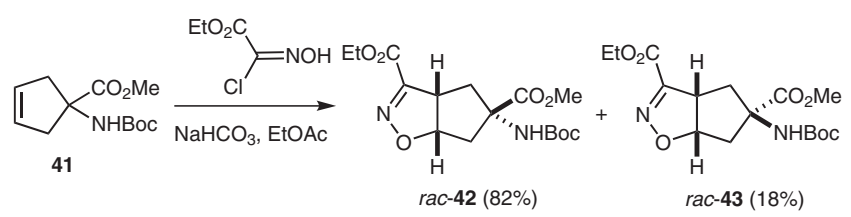

\section{Scheme 14}

The racemic cycloadducts $r a c-42$ and $r a c-43$ were obtained by the stereoselective cycloaddition of nitrile oxide to 41 (Scheme 14). When they were subjected to hydrolysis catalyzed by lipase B from Candida antarctica (CAL$\mathrm{B})$, the isoxazoline ester in $\mathrm{rac}-\mathbf{4 2}$ was transformed to the carboxylic function to furnish chemoselectively enantio- 


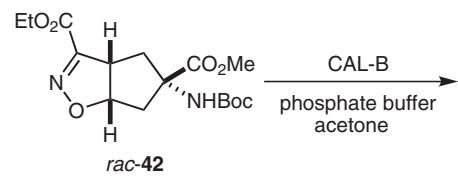

rac-42

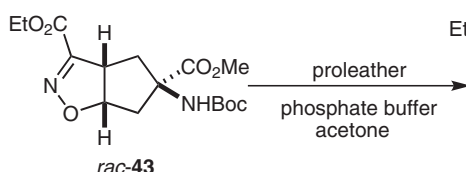

rac-43

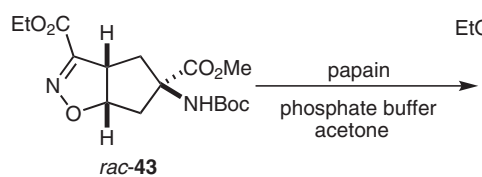

ac-43

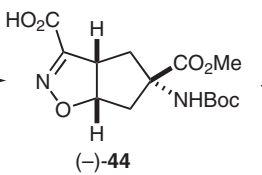

(-)-44

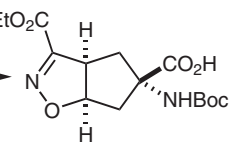

$(+)-45$

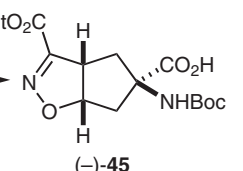

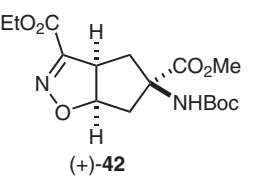

(+)-42

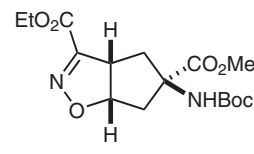

$(-)-43$

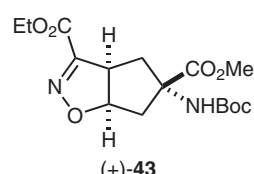

Scheme 15

mer (-)-44 and unreacted enantiomerically pure ester $(+)-$ 42. Hydrolysis of the alicyclic ester $r a c-\mathbf{4 3}$ by means of proleather chemoselective catalysis afforded amino acid enantiomer $(+)-45$ and unreacted ester enantiomer (-)-43, while papain catalyzed the hydrolysis of racemic diester rac-43 to the opposite monoacid enantiomer, (-)-45 (Scheme 15). ${ }^{10}$

These enantiomerically pure isoxazoline-fused monoacids and esters $\mathbf{4 2}-\mathbf{4 5}$ were then converted by ester hydrolysis and $\mathrm{N}$-deprotection into the corresponding optically pure bicyclic amino diacids.

In contrast with the Huisgen method, the Mukaiyama nitrile oxide generation technique provided isoxazolinefused $\alpha$-aminocyclopentanecarboxylates with higher stereoselectivity. Park and co-workers applied the Mukaiyama methodology to carry out the cycloadditions of nitrile oxides to $\alpha$-aminocyclopentenecarboxylates, the 1,3-dipolar reagents being generated from primary nitroalkanes. The nitrile oxide derived from 1-nitrobutane using phenyl isocyanate and triethylamine react with cis selectivity with urea derivative $\mathbf{4 7}$ under the control of the $\mathrm{H}$-bond directing effect of the urea moiety to furnish stereoisomers $\mathbf{4 9}$ and $\mathbf{4 8}$ in a ratio of 20:1 (5:1 by the Huisgen method), the major stereoisomer being that in which the isoxazoline and the urea displayed cis stereochemistry (Scheme 16). ${ }^{11}$

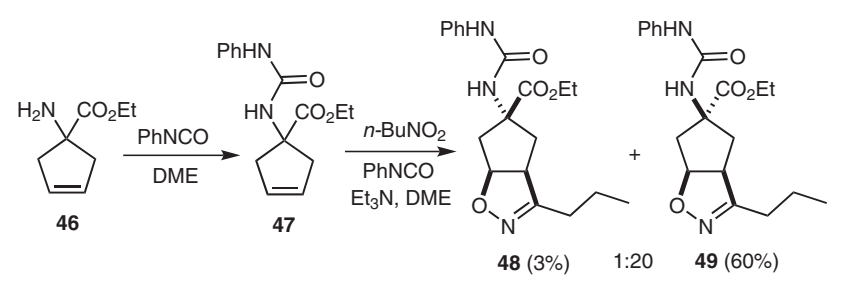

Scheme 16

The isoxazoline-fused $\alpha$-aminocyclopentanecarboxylate 48, in which the amino group and the heterocycle are trans, was obtained in only a very low amount from an Nmonoprotected (e.g., carbamate) amino ester, but this type of stereoisomer could be synthesized in a larger quantity by dipolar cycloaddition to an imino ester. Because of the absence of the H-bonding directing effect, the addition of the nitrile oxide (generated from nitrobutane/ $\mathrm{PhNCO} /$ $\left.\mathrm{Et}_{3} \mathrm{~N}\right)$ to imino ester $\mathbf{5 0}$ furnished isoxazoline-containing stereoisomers $\mathbf{5 1}$ and $\mathbf{5 2}$ in a ratio of 1:1 (Scheme 17). Since these isomers could not be separated, they were subjected to imine hydrolysis and treatment with phenyl isocyanate to give urea derivatives $\mathbf{5 5}$ and $\mathbf{5 6}$, which were separated and isolated (Scheme 17). Such compounds were subsequently transformed to cyclopentanes with hydantoin and isoxazoline moieties. ${ }^{11}$

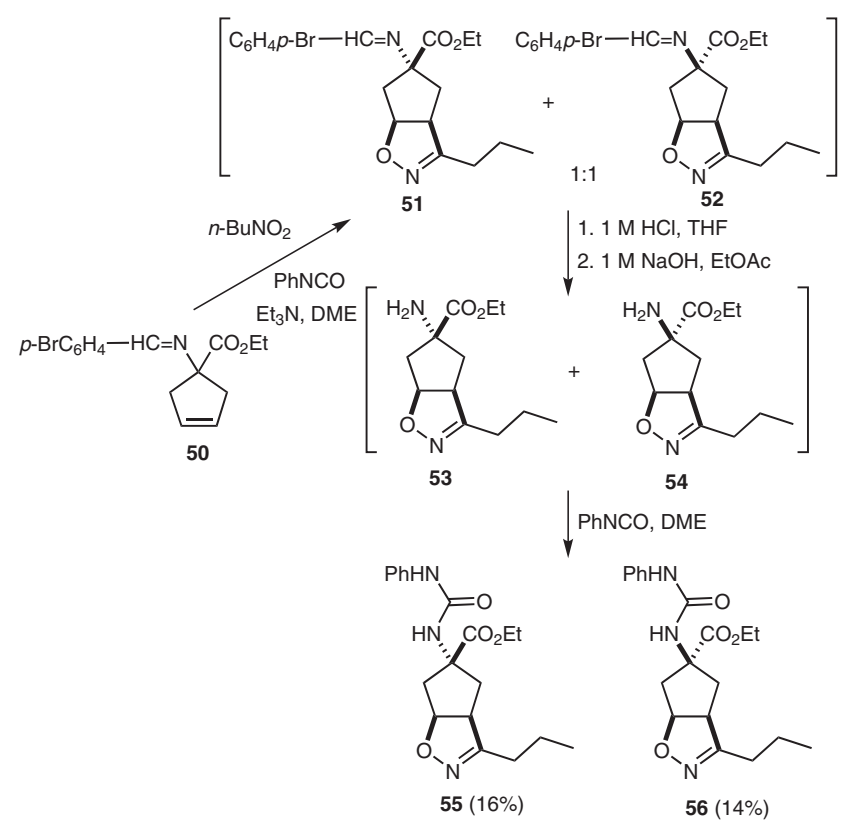

Scheme 17

Interestingly, in comparison with the additions of nitrile oxides to $\alpha$-aminocyclopentenecarboxylates (Schemes 12 and 14), addition to an $N$-Boc-protected cyclic $\alpha$-amino ester 57 possessing an extracyclic $\mathrm{C}=\mathrm{C}$ bond furnished the corresponding spiroisoxazoline cyclobutane amino esters with rather low stereoselectivity $(3: 1)$. The resulting spi- 
roisoxazolines 58 and $\mathbf{5 9}\left(\mathrm{R}=4-\mathrm{BrC}_{6} \mathrm{H}_{4}, \mathrm{Bu}, \mathrm{Ph}\right)$ were separated by chromatography (Scheme 18) and transformed into isoxazoline-substituted cyclobutanes. ${ }^{12}$

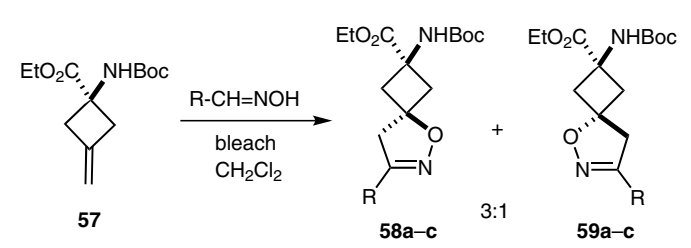

Scheme 18

Addition of the nitrile oxide generated from nitrobutane, phenyl isocyanate, and triethylamine by the Mukaiyama method to $N$-Boc-protected ethyl $\alpha$-aminocyclopentenecarboxylate $\mathbf{3 1}$ led exclusively by cis-selective addition to isoxazoline-fused $N$-Boc-amino ester $\mathbf{6 0}$, which was $\mathrm{N}$ deprotected to give amino ester $\mathbf{6 1}$ (Scheme 19). On coupling with a Boc-protected $\alpha$-aminocyclopent-3-enecarboxylic acid, $\mathbf{6 1}$ gave the dipeptidic derivative $\mathbf{6 2}$, which was subjected to nitrile oxide cycloaddition. Somewhat surprisingly, cycloaddition under the Mukaiyama conditions was not selective and afforded the corresponding cycloadducts 63 and 64 in a ratio of 1:1 (Scheme 19). ${ }^{13}$

\subsection{Syntheses of Isoxazoline $\gamma$-Amino Acids and Their Transformation into Bioactive Deriva- tives}

Intensive research investigations have been performed on the cycloaddition of various nitrile oxides to cyclopentane $\gamma$-aminocarboxylates. Since the isoxazoline-fused derivatives formed are precursors of the anti-influenza agent Peramivir (72) and its analogues, ${ }^{14}$ such syntheses are of great importance in synthetic and medicinal chemistry.

The nitrile oxide suitable for the synthesis of anti-influenza agent $\mathbf{7 2}$ was generated from 3-(nitromethyl)pentane, phenyl isocyanate, and triethylamine. Although the cycloaddition of this nitrile oxide was performed to an $N$-Bocprotected amino ester $(-)-\mathbf{6 5}$, in contrast with the earlier presented cycloadditions (e.g., to $N$-Boc-protected $\alpha$-aminocyclopentenecarboxylates), in this case the $\mathrm{H}$-bond di- recting effect was not observed. The reaction afforded four regio- and stereoisomers 66-69, the major isomer being that one in which the isoxazoline ring and the carbamate group are trans in $\mathbf{6 6}$, while the oxygen atom of the heterocycle is farthest from the carbamate (Scheme 20). ${ }^{14 a}$ This result may be explained by steric factors: due to the large alkyl chain of the nitrile oxide, steric repulsions overcome the H-bond directing effect in the transition state.

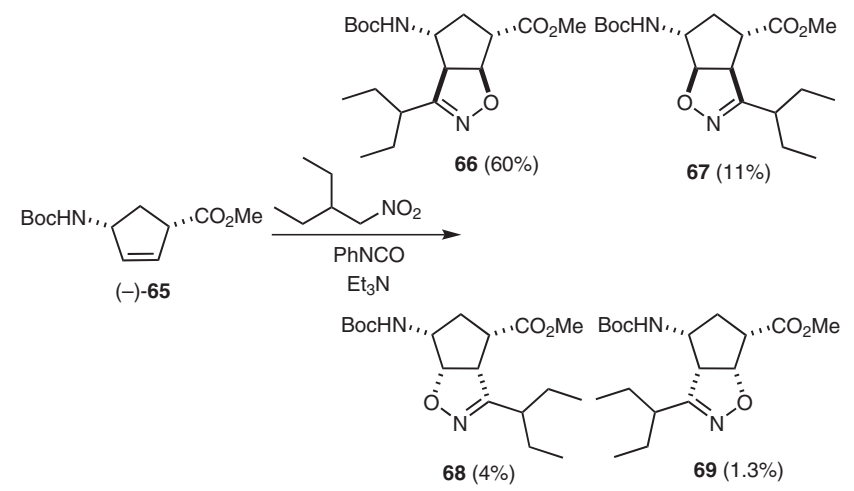

Scheme 20

The major isoxazoline-based amino ester $\mathbf{6 6}$ was separated from the other isomers by chromatography, and subsequent reductive isoxazoline opening, $N$-Boc deprotection, guanidinylation, and ester hydrolysis gave the target neuraminidase inhibitor Peramivir enantiomer (-)-72 (Scheme 21).

The isoxazoline ring-opened intermediate $\mathbf{7 0}$ was transformed by reductive removal of the cyclopentane hydroxy group to give 74, followed by deprotection and guanidinylation to give $\mathbf{7 6}$, to yield Peramivir analogue $\mathbf{7 7}$ (Scheme 22). ${ }^{14 a}$

While the additions of nitrile oxides to $\alpha$-aminocyclopentenecarboxylates were only selective under Mukaiyama conditions (cf. Schemes 13 and 19), for the corresponding $\gamma$-analogues the Huisgen method proved to be $100 \%$ regio- and stereoselective. Addition of the nitrile oxide generated from 2-ethylbutanal oxime and sodium hypo-

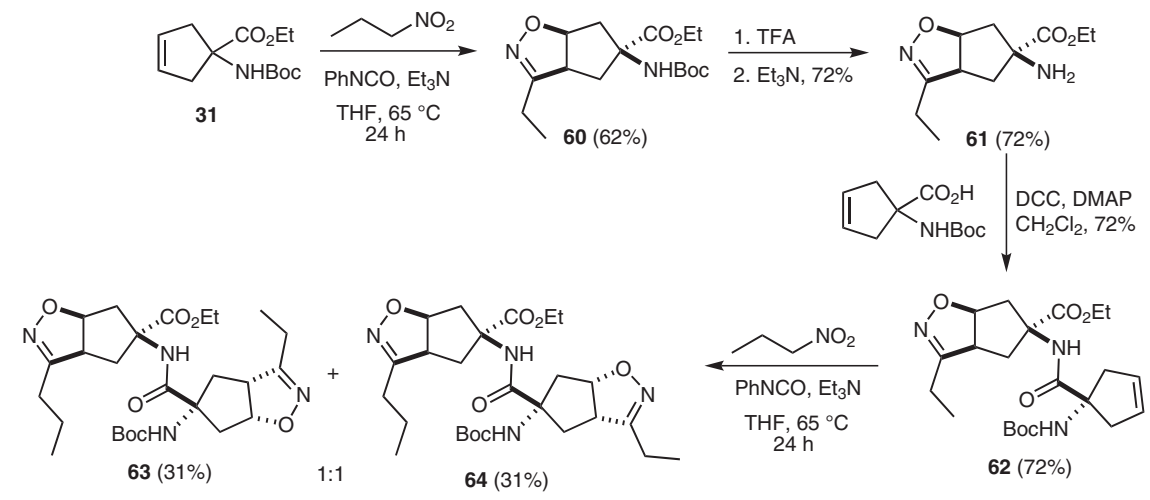

Scheme 19 


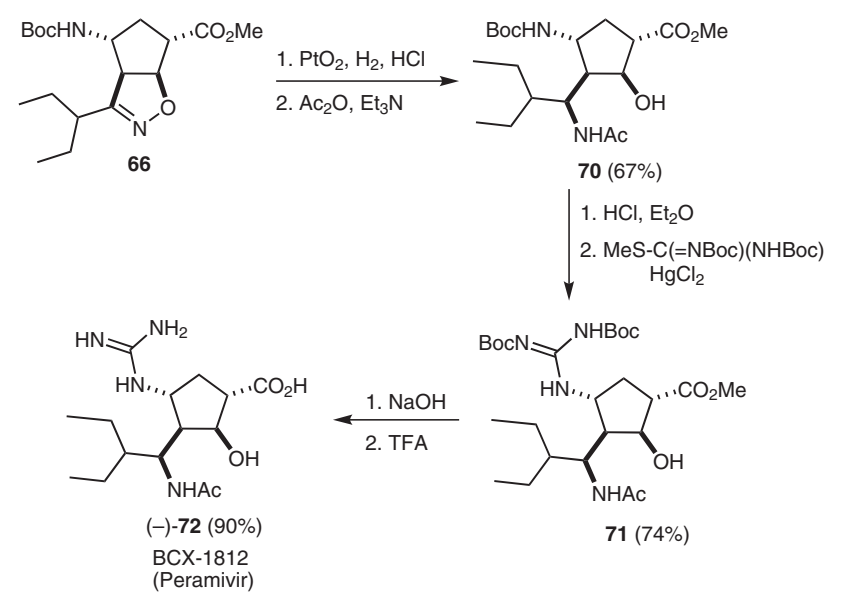

Scheme 21

chlorite in the presence of triethylamine to the cyclopentene $c i s-\gamma$-amino ester $\mathbf{6 5}$ resulted completely regio- and stereoselectively in exclusively isoxazoline-fused amino ester 66 (Scheme 23).

Compound 66 was then transformed by standard methods to racemic Peramivir rac-72. ${ }^{15}$

Peramivir analogues with a modified side chain have been prepared by the addition of the nitrile oxide generated from 4-(nitromethyl)heptane to amino ester $\mathbf{6 5}$. The major product 78 was purified by chromatography from the minor isomers (Scheme 24), and was next converted efficiently into Peramivir analogues $\mathbf{7 9}$ and 80 (Figure 4). ${ }^{16}$

Dipolar cycloadditions of nitrile oxides have likewise been applied in the syntheses of other Peramivir analogues. The nitrile oxide generated from nitropentane by addition to cyclopentenecarboxylate $\mathbf{8 1}$ resulted in isoxazoline derivatives 82 and $\mathbf{8 3}$ in a ratio of approximately $4: 1$, the major product $\mathbf{8 2}$ being favored for steric reasons (Scheme 25).

The major isomer $\mathbf{8 2}$ was subjected to isoxazoline reductive opening, followed by hydroxy-amino interconversion, guanidinylation, and deprotection to afford finally 88 (Scheme 26). ${ }^{14 a}$

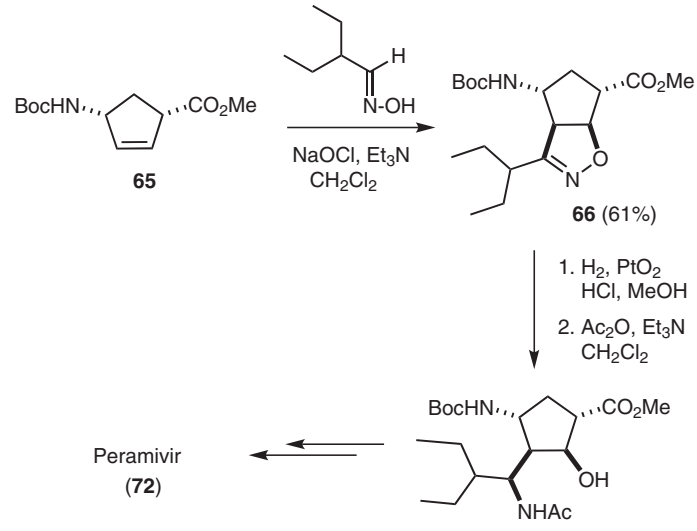

$70(82 \%)$

Scheme 23

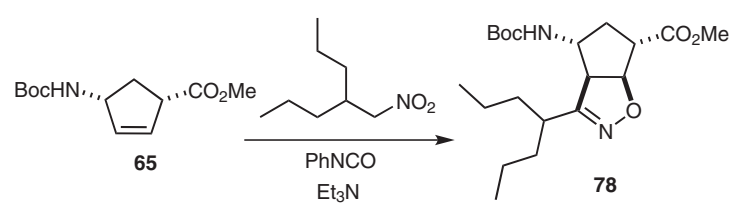

Scheme 24
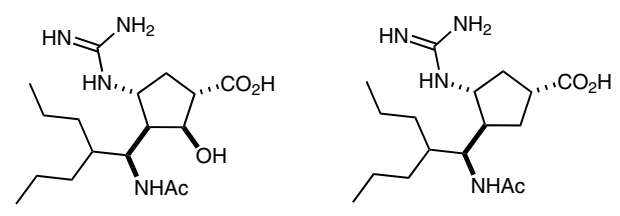

BCX-1923 (79)

BCX-1898 (80)

Figure 4

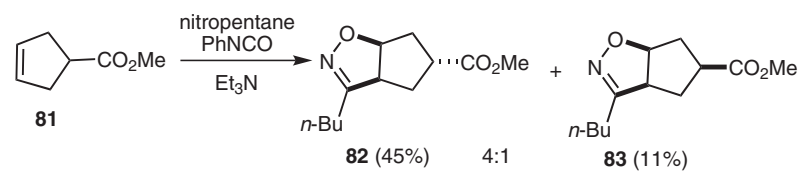

Scheme 25
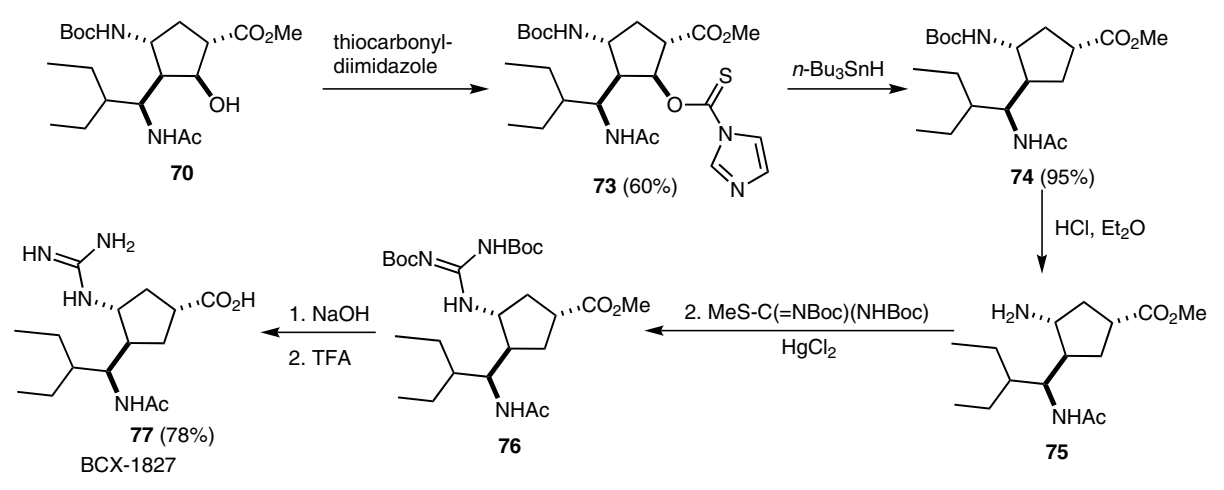

Scheme 22 


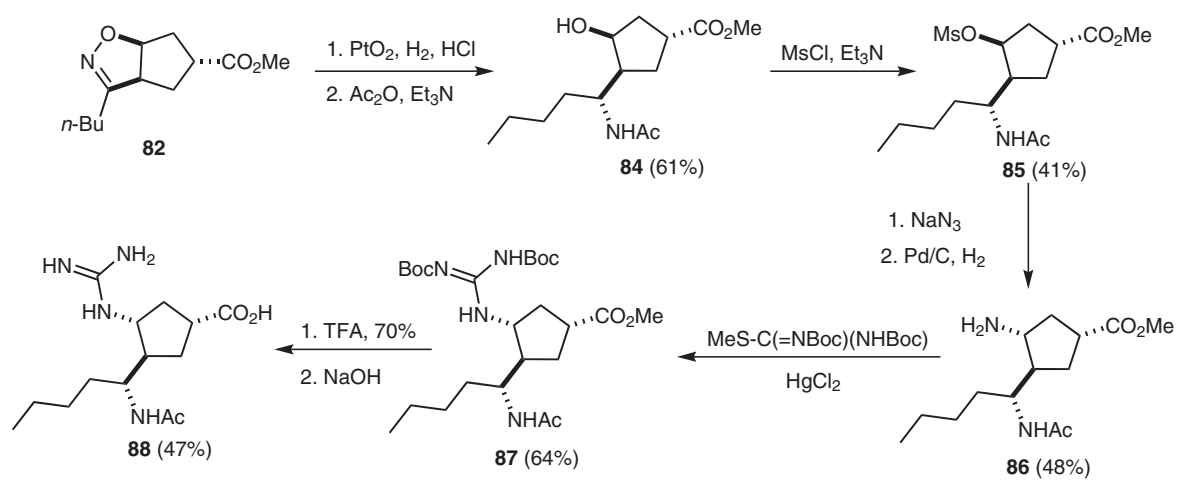

Scheme 26

\subsection{Syntheses of Isoxazoline $\beta$-Amino Acids}

In view of their valuable pharmacological properties, $\beta$ amino acids are an important class of compounds in amino acid chemistry, and have become a hot topic in synthetic and medicinal chemistry in the past 15 years. ${ }^{17}$ Cycloadditions of nitrile oxides to cycloalkene $\beta$-amino acids have been efficiently applied for their functionalization.

Addition ethyl cis-2-aminocyclopentenecarboxylate (89) and methyl- or ethyl-substituted nitrile oxides, derived from nitroethane or nitropropane and di-tert-butyl dicarbonate and 4-(dimethylamino)pyridine, gave, of the four possible isoxazoline-fused regio- and stereoisomers, three derivatives 90-92; the major stereoisomer 90 was that in which the carbamate function and isoxazoline skeleton are trans and the oxygen atom of the isoxazoline ring is farthest from the carbamate (Scheme 27). ${ }^{18}$ The selectivity was explained and supported by theoretical calculations in terms of the H-bond directing interaction in the transition state of the reaction (Figure 5). ${ }^{19}$

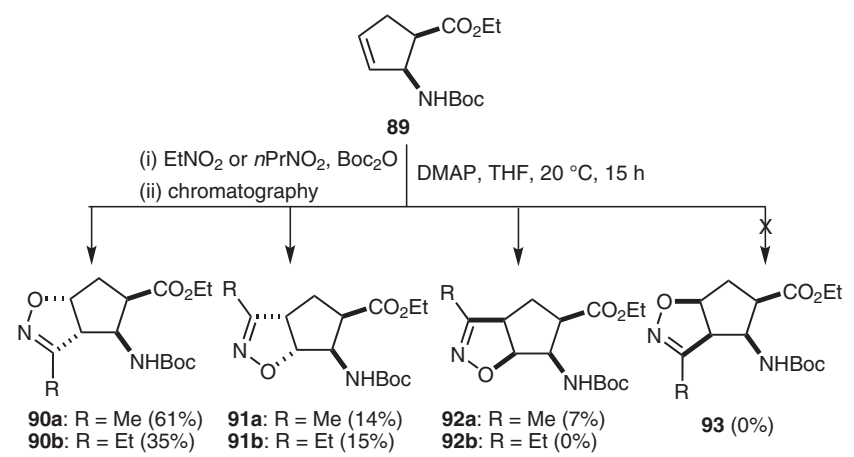

Scheme 27

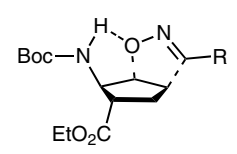

Figure 5

Interestingly, when the nitrile oxide was generated from the primary nitroalkane and phenyl isocyanate in the presence of triethylamine, the cycloadditions gave cycloadduct 90 (which was the major product under the previous conditions) with $100 \%$ regio- and stereoselectivity (Scheme 28). ${ }^{19}$ The reason for this unexpected experimental observation was not clarified.

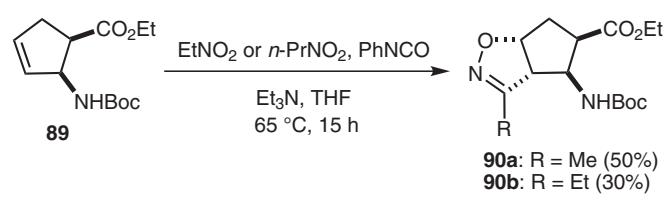

Scheme 28

The addition to cis-amino ester $\mathbf{8 9}$ was not totally selective when the nitrile oxide was generated from nitroalkane, di-tert-butyl dicarbonate, and 4-(dimethylamino)pyridine, however, a very surprising result was found when the addition was carried out with trans $\beta$-aminocyclopentenecarboxylate 94 under similar conditions. The reaction yielded, with complete regio- and stereoselectivity, isoxazoline-fused aminocyclopentanecarboxylate 95 (Scheme 29). ${ }^{19}$

In contrast to the reactions of $\mathbf{8 9}$, the addition of nitrile oxides generated from nitroalkane, phenyl isocyanate, and triethylamine to di- $N$-Boc-protected ester 99 selectively furnished, but with the opposite selectivity, low yields of isoxazoline-fused $\beta$-aminocyclopentanecarboxylates 100 (Scheme 30). ${ }^{19}$ 


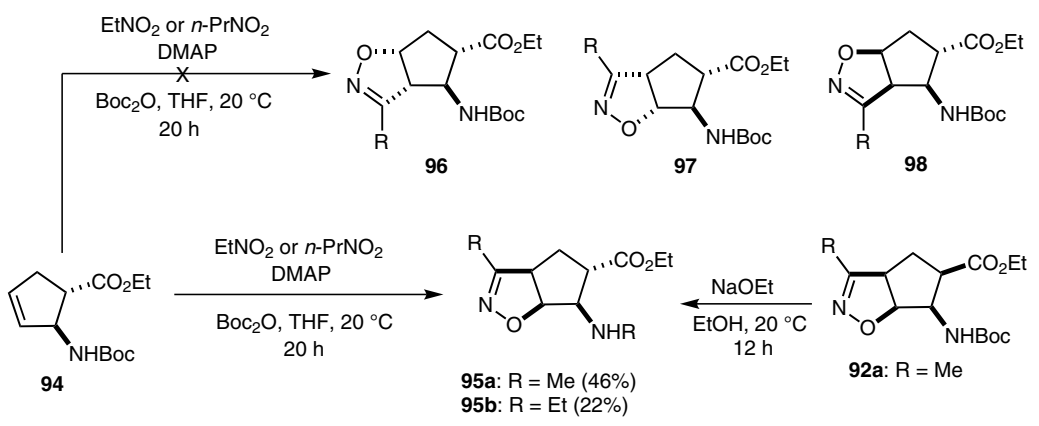

Scheme 29

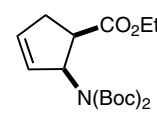

99

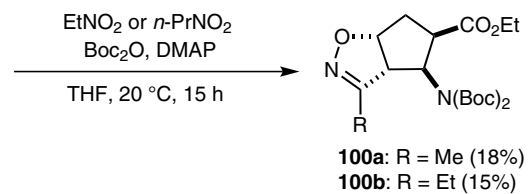

Scheme 30

\subsubsection{Syntheses of Highly Functionalized Cyclic $\beta$ - Amino Acids by 1,3-Dipolar Cycloaddition of Nitrile Oxides}

Dipolar cycloadditions of nitrile oxides have been efficiently applied to produce highly functionalized cyclic $\beta$ amino acid derivatives. Although attempts to prepare isoxazoline-fused hydroxylated $\beta$-aminocyclohexanecarboxylates 105 or 106 by the addition of nitrile oxides to the olefinic bond of hydroxylated cyclohexenecarboxylates $\mathbf{1 0 1}$ or $\mathbf{1 0 2}$ proved unsuccessful, these compounds were prepared in an alternative way, by means of the cisselective addition of nitrile oxide to the unsaturated lactone $\mathbf{1 0 3}$, followed by lactone ring opening with sodium ethoxide. Lactone ring opening at $0{ }^{\circ} \mathrm{C}$ furnished the allcis amino ester 105, while at $20^{\circ} \mathrm{C}$ epimerization occurred to give stereoisomer 106 (Scheme 31). ${ }^{20}$

Highly functionalized cyclopentane $\beta$-amino esters have been synthesized by reductive isoxazoline ring cleavage. On treatment with sodium borohydride and nickel(II) chloride, the reaction of amino ester 90a proceeded with cis selectivity to give $\mathbf{1 0 7}$ (Scheme 32).<smiles>CCOC(=O)C1C[C@@H]2ON=C(C)[C@H]2C1NC(=O)OCc1ccccc1</smiles>
$\underset{\text { EtOH-THF (3:1), r.t., } 6 \mathrm{~h}}{\stackrel{\mathrm{NaBH}_{4}, \mathrm{NiCl}_{2}, \mathrm{Boc}_{2} \mathrm{O}}{\longrightarrow}}$

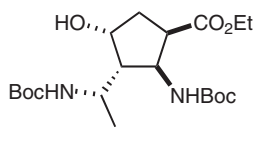

$107(80 \%)$

\section{Scheme 32}

Other multisubstituted cispentacin stereoisomers 108111 were prepared by the same protocol from isoxazolinefused 2-aminocyclopentanecarboxylates (Figure 6). ${ }^{21}$

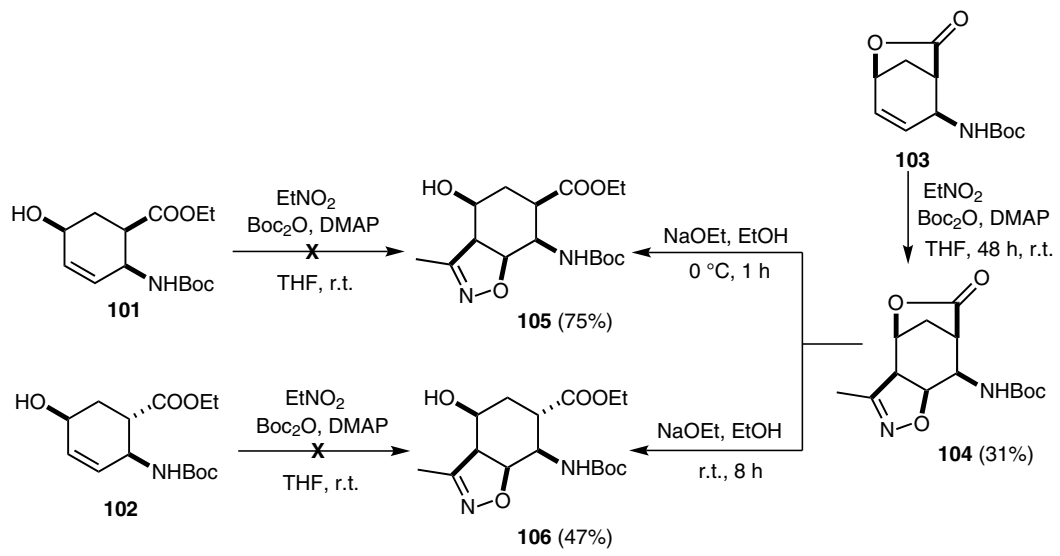

Scheme 31 
<smiles>CCO[C@H]1C[C@@H](O)[C@H]([C@H](C)NC(=O)c2ccccc2)[C@H]1N[13C](=O)[O-]</smiles><smiles>CCOC(=O)NC1[C@@H](O)C([C@H](C)NC(=O)OCc2ccccc2)C[C@H]1C(=O)OCC</smiles>

Figure 6

\section{$4 \quad$ Cycloaddition of Nitrile Oxides to Amino Acid Precursors}

Next the syntheses of isoxazoline-containing derivatives, which may be regarded as cyclic amino acid precursors, were investigated. Addition of the nitrile oxide obtained from benzhydroximoyl chloride (113) and triethylamine to azabicyclic derivative $\mathbf{1 1 2}$ stereoselectively furnished isoxazoline-fused cycloadduct regioisomers 114 and $\mathbf{1 1 5}$ in a ratio of approximately $1: 1$. After separation by chromatography, these compounds were transformed via isoxazoline amino alcohols 116 and 117, with purine and pyrimidine base construction, to a series of isoxazolinefused carbocyclic nucleosides (Scheme 33). ${ }^{22}$

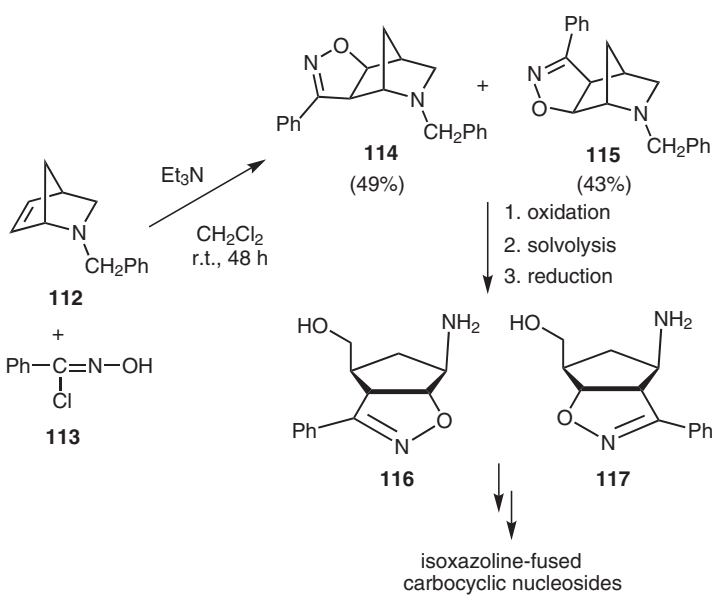

\section{Scheme 33}

Isoxazoline $\gamma$-lactams, as precursors of $\gamma$-amino acids, are readily accessible from azacyclic derivatives $\mathbf{1 1 4}$ and 115. Oxidation of these two compounds with ruthenium tetroxide and sodium periodate afforded $\gamma$-lactam derivatives $\mathbf{1 1 8} / \mathbf{1 2 0}$ and 121/123, respectively, in rather low yields. Oxidation at the benzylic position led to 119 and 122 (Scheme 34). ${ }^{23}$

On treatment with methanesulfonic acid, isoxazoline $\gamma$ lactams 118 and 121 underwent ready conversion into the corresponding isoxazoline $\gamma$-amino acid derivatives 124 and 125 (Scheme 35). ${ }^{23}$
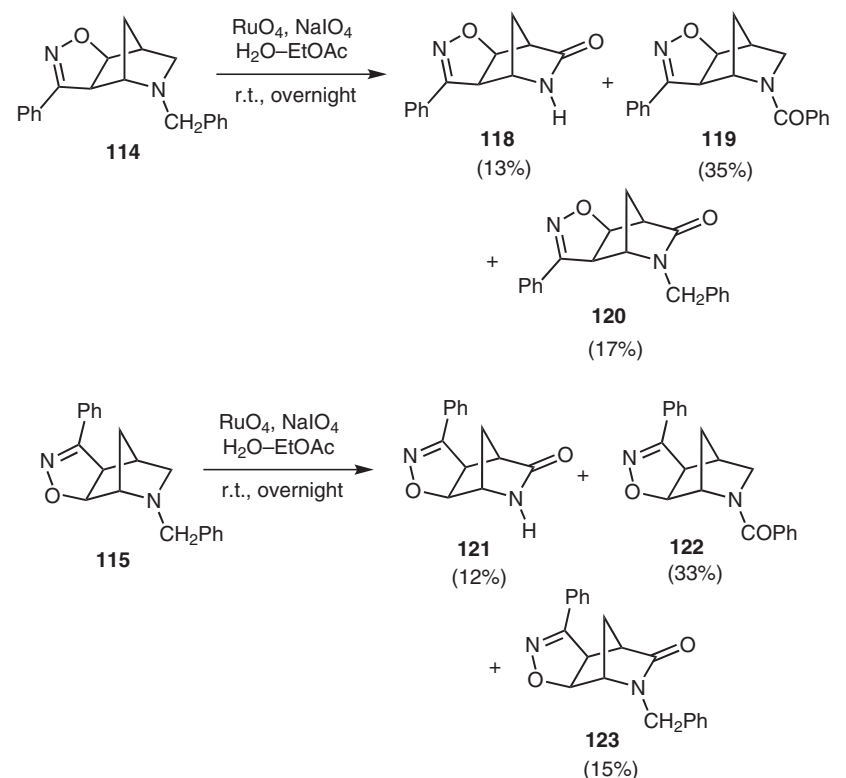

Scheme 34
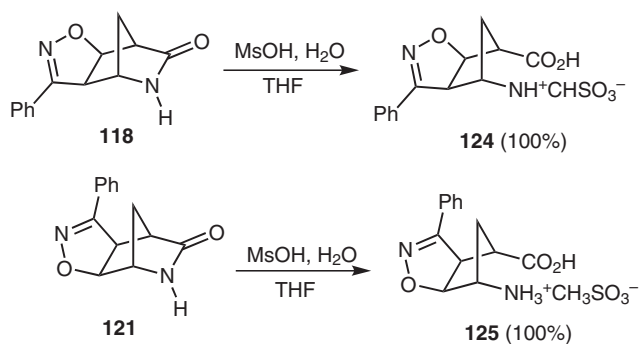

Scheme 35

In order to increase the amount of the isoxazoline $\gamma$-lactam, isoxazoline-based azacyclic regioisomers 127 and 128 were first prepared analogously to the process shown in Scheme 34, by changing the N-substituent from benzyl to methyl, ethyl, isopropyl, or tert-butyl (Scheme 36). ${ }^{24}$

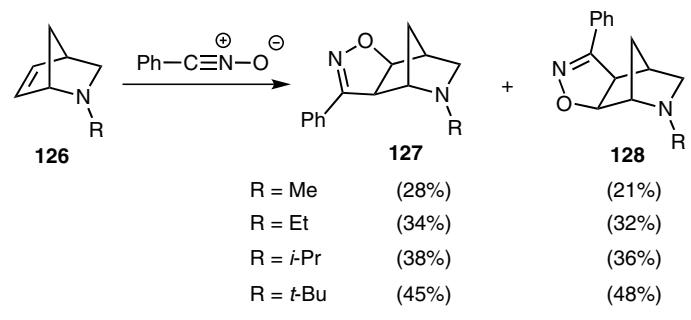

Scheme 36

Both isoxazoline regioisomers $\mathbf{1 2 7}$ and $\mathbf{1 2 8}$ were then subjected to the oxidation reaction. Though the compounds bearing an $N$-ethyl or $N$-isopropyl group gave only poor yields of the corresponding lactam, the tert-butyl derivatives of both 127 and $\mathbf{1 2 8}$ resulted selectively in only the isoxazoline $\gamma$-lactams 129 and 132 in high yields (Schemes 37 and 38). ${ }^{23}$ 


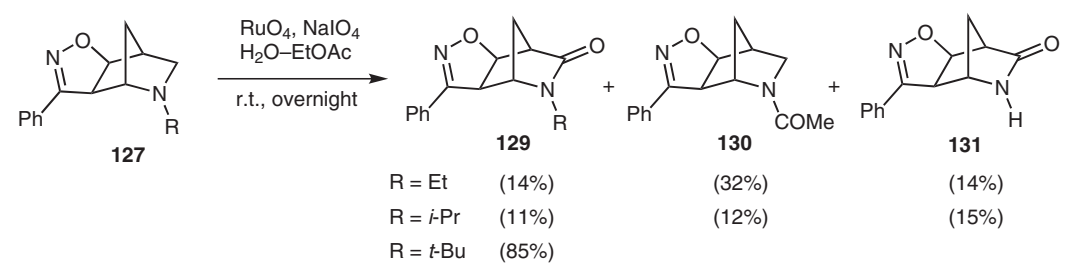

Scheme 37
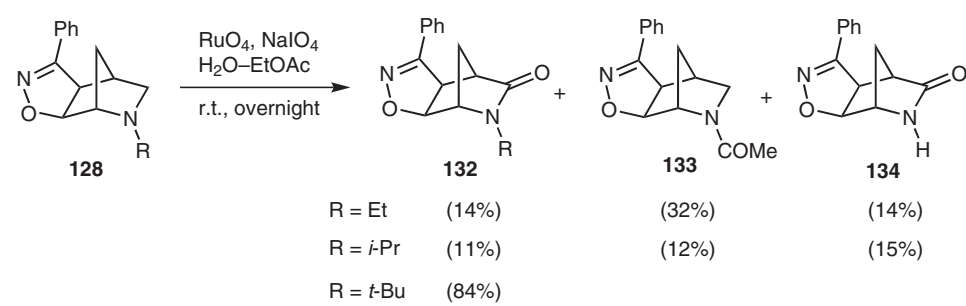

Scheme 38

\section{5}

\section{Summary and Outlook}

Highly functionalized cyclic amino acids are valuable bioactive substances and, therefore, potentially extremely important in synthetic and medicinal chemistry. The regio- and stereoselective dipolar cycloaddition of nitrile oxides is a powerful technique for construction of the isoxazoline ring, and is a widely applicable method for the functionalization of various amino acid derivatives containing an olefinic bond. Moreover, reductive isoxazoline ring cleavage offers an opportunity for access to a number of highly functionalized cyclic amino acid derivatives with the generation of new stereogenic centers, which is likely to have a considerable impact in medicinal chemistry.

\section{Acknowledgment}

We are grateful to the Hungarian Research Foundation (OTKA No. NK81371 and K100530) for financial support and acknowledge the receipt of a Bolyai János Fellowship for Loránd Kiss.

\section{References}

(1) (a) Fuller, A. A.; Chen, B.; Minter, A. R.; Mapp, A. K. J. Am. Chem. Soc. 2005, 127, 5376. (b) Bode, J. W.; Fraefel, N.; Muri, D.; Carreira, E. M. Angew. Chem. Int. Ed. 2001, 40, 2082. (c) Tangallapally, R. P.; Rakesh, D. S.; Budha, N.; Lee, R. E. B.; Lenaerts, A. J. M.; Meibohm, B.; Lee, R. E. Bioorg. Med. Chem. Lett. 2007, 17, 6638. (d) Sielecki, T. M.; Liu, J.; Mousa, S. A.; Racanelli, A. L.; Hausner, E. A.; Wexler, R. R.; Olson, R. E. Bioorg. Med. Chem. Lett. 2001, 11, 2201. (e) Gaonkar, S. L.; Rai, K. M. L.; Prabhuswamy, B. Med. Chem. Res. 2007, 15, 407. (f) Kozikowski, A. P.; Tapadar, S.; Luchini, D. N.; Kim, K. H.; Billadeau, D. D. J. Med. Chem. 2008, 51, 4370. (g) Kai, H.; Matsumoto, H.; Hattori, N.; Takase, A.; Fujiwara, T.; Sugimoto, H. Bioorg.
Med. Chem. Lett. 2001, 11, 1997. (h) Basappa, M.; Sadashiva, P.; Mantelingu, K.; Swamy, N. S.; Rangappa, K. S. Bioorg. Med. Chem. 2003, 11, 4539. (i) Lam, P. Y. S.; Adams, J. J.; Clark, C. G.; Calhoun, W. J.; Luettgen, J. M.; Knabb, R. M.; Wexler, R. R. Bioorg. Med. Chem. Lett. 2003, 13, 1795. (j) Barbachyn, M. R.; Cleek, G. J.; Dolak, L. A.; Garmon, S. A.; Morris, J.; Seest, E. P.; Thomas, R. C.; Toops, D. S.; Watt, W.; Wishka, D. G.; Ford, C. W.; Zurenko, G. E.; Hamel, J. C.; Schaadt, R. D.; Stapert, D.; Yagi, B. H.; Adams, W. J.; Friis, J. M.; Slatter, J. G.; Sams, J. P.; Oien, N. L.; Zaya, M. J.; Wienkers, L. C.; Wynalda, M. A. J. Med. Chem. 2003, 46, 284. (k) Pirrung, M. C.; Tumey, L. N.; Raetz, C. R. H.; Jackman, J. E.; Snehalatha, K.; McClerren, A. L.; Fierke, C. A.; Gantt, S. L.; Rusche, K. M. J. Med. Chem. 2002, 45, 4359.

(2) (a) Najera, C.; Sansano, J. M. Org. Biomol. Chem. 2009, 7, 4567. (b) Kissane, M.; Maguire, A. R. Chem. Soc. Rev. 2010, 39, 845 .

(3) (a) Cycloaddition Reactions in Organic Synthesis; Kobayashi, S.; Jorgensen, K. A., Eds.; Wiley-VCH: Weinheim, 2002. (b) Nitrile Oxides, Nitrones and Nitronates in Organic Synthesis; Torsell, K. B. G., Ed.; VCH: New York, 2008. (c) Pellissier, H. Tetrahedron 2007, 63, 3235. (d) Namboothiri, I. N. N.; Rastogi, N.; Ganguly, B.; Mobin, S. M.; Cojocaru, M. Tetrahedron 2004, 60, 1453. (e) Dell, C. P. J. Chem. Soc., Perkin Trans. 1 1998, 3873.

(f) Gallos, J. K.; Koumbis, A. E. Curr. Org. Chem. 2003, 7, 397. (g) Nair, V.; Suja, T. D. Tetrahedron 2007, 63, 12247. (h) Engels, B.; Christl, M. Angew. Chem. Int. Ed. 2009, 48, 7968. (i) Kanemasa, S. Synlett 2002, 1371. (j) Stanley, L. M.; Sibi, M. P. Chem. Rev. 2008, 108, 2887.

(4) (a) Shing, T. K. M.; Wong, W. F.; Cheng, H. M.; Kwok, W. S.; So, K. H. Org. Lett. 2007, 9, 753. (b) Mendelsohn, B. A.; Lee, S.; Kim, S.; Teyssler, F.; Aulakh, V. S.; Ciufolini, M. A. Org. Lett. 2009, 11, 1539.

(5) (a) Gothelf, K. V.; Jorgensen, K. A. Chem. Rev. 1998, 98 , 863. (b) Jiang, D.; Chen, Y. J. Org. Chem. 2008, 73, 9181. (c) Tang, S.; He, J.; Sun, Y.; He, L.; She, X. J. Org. Chem. 2010, 75, 1961. (d) Bode, J. W.; Carreira, E. M. Org. Lett. 2001, 3, 1587. (e) Tokizane, M.; Sato, K.; Ohta, T.; Ito, Y. 
Tetrahedron: Asymmetry 2008, 19, 2519. (f) Minter, A. R.; Fuller, A. A.; Mapp, A. K. J. Am. Chem. Soc. 2003, 125, 6846. (g) Fuller, A. A.; Chen, B.; Minter, A. R.; Mapp, A. K. J. Am. Chem. Soc. 2005, 127, 5376. (h) Sewald, N. Angew. Chem. Int. Ed. 2003, 42, 5794.

(6) Conti, P.; Caligiuri, A.; Pinto, A.; Roda, G.; Tamborini, L.; Nielsen, B.; Madsen, U.; Frydenvang, K.; Colombo, A.; De Micheli, C. Eur. J. Med. Chem. 2007, 42, 1059.

(7) Pinto, A.; Conti, P.; De Amici, M.; Tamborini, L.; Grazioso, G.; Colleoni, S.; Mennini, T.; Gobbi, M.; De Micheli, C. Tetrahedron: Asymmetry 2008, 19, 867.

(8) Pinto, A.; Conti, P.; Grazioso, G.; Tamborini, L.; Madsen, U.; Nielsen, B.; De Micheli, C. Eur. J. Med. Chem. 2011, 46, 787.

(9) Conti, P.; De Amici, M.; Joppolo di Ventimiglia, S.; Stensbol, T. B.; Madsen, U.; Bräuner-Osborne, H.; Russo, E.; De Sarro, G.; Bruno, G.; De Micheli, C. J. Med. Chem. 2003, 46, 3102.

(10) Roda, G.; Conti, P.; De Amici, M.; He, J.; Polavarapu, P. L.; De Micheli, C. Tetrahedron: Asymmetry 2004, 15, 3079.

(11) Park, K.-H.; Olmstead, M. M.; Kurth, M. J. J. Org. Chem. 1998, 63, 113.

(12) Park, K.-H.; Kurth, M. J. J. Org. Chem. 2000, 65, 352.

(13) Park, K.-H.; Olmstead, M. M.; Kurth, M. J. Synlett 2003, 1267.

(14) (a) Chand, P.; Kotian, P. L.; Dehghani, A.; El-Kattan, Y.; Lin, T.; Hutchison, T. L.; Babu, Y. S.; Bantia, S.; Elliott, A. J.; Montgomery, J. A. J. Med. Chem. 2001, 44, 4379. (b) Oakley, A. J.; Barrett, S.; Peat, T. S.; Newman, J.; Streltsov, V. A.; Waddington, L.; Saito, T.; Tashiro, M.; McKimm-Breschkin, J. L. J. Med. Chem. 2010, 53, 6421. (c) Lu, W. J.; Chen, Y. L.; Ma, W. P.; Zhang, X. Y.; Luan, F.; Liu, M. C.; Chen, X. G.; Hu, Z. D. Eur. J. Med. Chem. 2008, 43, 569. (d) Cui, Y.; Jiao, Z.; Gong, J.; Yu, Q.; Zheng, X.; Quan, J.; Luo, M.; Yang, Z. Org. Lett. 2010, 12, 4. (e) Yi, X.; Guo, Z.; Chu, F. M. Bioorg. Med. Chem. 2003, 11, 1465.
(15) Mineno, T.; Miller, M. J. J. Org. Chem. 2003, 68, 6591.

(16) (a) Chand, P.; Bantia, S.; Kotian, P. L.; El-Kattan, Y.; Lin, T.-H.; Babu, S. Y. Bioorg. Med. Chem. 2005, 13, 4071. (b) Chand, P.; Babu, Y. S.; Bantia, S.; Rowland, S.; Deghghani, A.; Kotian, P. L.; Hitchison, T. L.; Ali, S.; Brouillette, W.; El-Kattan, Y.; Lin, T.-H. J. Med. Chem. 2004, 47, 1919. (c) Yi, X.; Guo, Z.; Chu, F. M. Bioorg. Med. Chem. 2003, 11, 1465.

(17) (a) Kiss, L.; Forró, E.; Fülöp, F. Synthesis of Carbocyclic $\beta$ Amino Acids, In Amino Acids, Peptides and Proteins in Organic Chemistry; Vol. 1; Hughes, A. B., Ed.; Wiley: Weinheim, 2009, 367. (b) Kiss, L.; Fülöp, F. Synlett 2010, 1302; and references cited herein.

(18) Kiss, L.; Nonn, M.; Forró, E.; Sillanpää, R.; Fülöp, F. Tetrahedron Lett. 2009, 50, 2605.

(19) Nonn, M.; Kiss, L.; Forró, E.; Mucsi, Z.; Fülöp, F. Tetrahedron 2011, 67, 4079.

(20) Nonn, M.; Kiss, L.; Sillanpää, R.; Fülöp, F. unpublished results.

(21) Nonn, M.; Kiss, L.; Sillanpää, R.; Fülöp, F. Beilstein J. Org. Chem. 2012, 8, 100.

(22) (a) Quadrelli, P.; Picanello, A.; Martinez, N. V.; Bovio, B.; Mella, M.; Caramella, P. Tetrahedron 2006, 62, 7370. (b) Quadrelli, P.; Piccanello, A.; Mella, M.; Corsaro, A.; Pistara, V. Tetrahedron 2008, 64, 3541. (c) Quadrelli, P.; Mella, M.; Assanelli, G.; Picanello, A. Tetrahedron 2008, 64, 7312. (d) Quadrelli, P.; Bovio, B.; Piccinini, A.; Caramella, P.; De Sarlo, F.; Machetti, F. Tetrahedron 2009, 65, 10679. (e) Savion, M.; Memeo, M. G.; Bovio, B.; Grazioso, G.; Legnani, L.; Quadrelli, P. Tetrahedron 2012, 68, 1845. (f) Moggio, Y.; Legnani, L.; Bovio, B.; Memeo, M. G.; Quadrelli, P. Tetrahedron 2012, 68, 1384.

(23) Memeo, M. G.; Bovio, B.; Quadrelli, P. Tetrahedron 2011, 67, 1907.

(24) Memeo, M. G.; Mantione, D. P.; Bovio, B.; Quadrelli, P. Synthesis 2011, 2165. 